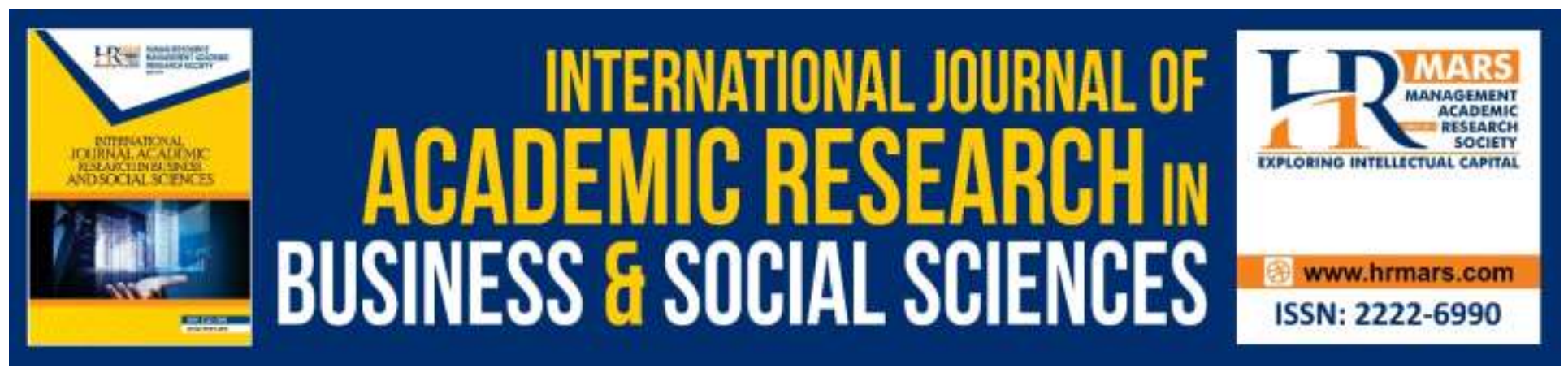

\title{
Investigating the Relationship Between Stress and Psychological Well-Being among Foundation Students of UiTM
}

Melissa Malik, Norshiha Saidin, Roslinda Abd Wab, and Norshidah Nordin

To Link this Article: http://dx.doi.org/10.6007/IJARBSS/v10-i14/7366

DOI:10.6007/IJARBSS/v10-i14/7366

Received: 15 April 2020, Revised: 18 May 2020, Accepted: 14 June 2020

Published Online: 28 June 2020

In-Text Citation: (Malik et al., 2020)

To Cite this Article: Malik, M., Saidin, N., Wab, R. A., \& Nordin, N. (2020). Investigating the Relationship Between Stress and Psychological Well-Being Among Foundation Students of UiTM. International Journal of Academic Research in Business and Social Sciences, 10(14), 93-101.

Copyright: (C) 2020 The Author(s)

Published by Human Resource Management Academic Research Society (www.hrmars.com)

This article is published under the Creative Commons Attribution (CC BY 4.0) license. Anyone may reproduce, distribute, translate and create derivative works of this article (for both commercial and non-commercial purposes), subject to full attribution to the original publication and authors. The full terms of this license may be seen

at: http://creativecommons.org/licences/by/4.0/legalcode

Special Issue: WSTI2018 - Issues and Trends on Education, Science and Technology, 2020, Pg. 93 - 101

http://hrmars.com/index.php/pages/detail/IJARBSS

JOURNAL HOMEPAGE

Full Terms \& Conditions of access and use can be found at

http://hrmars.com/index.php/pages/detail/publication-ethics 


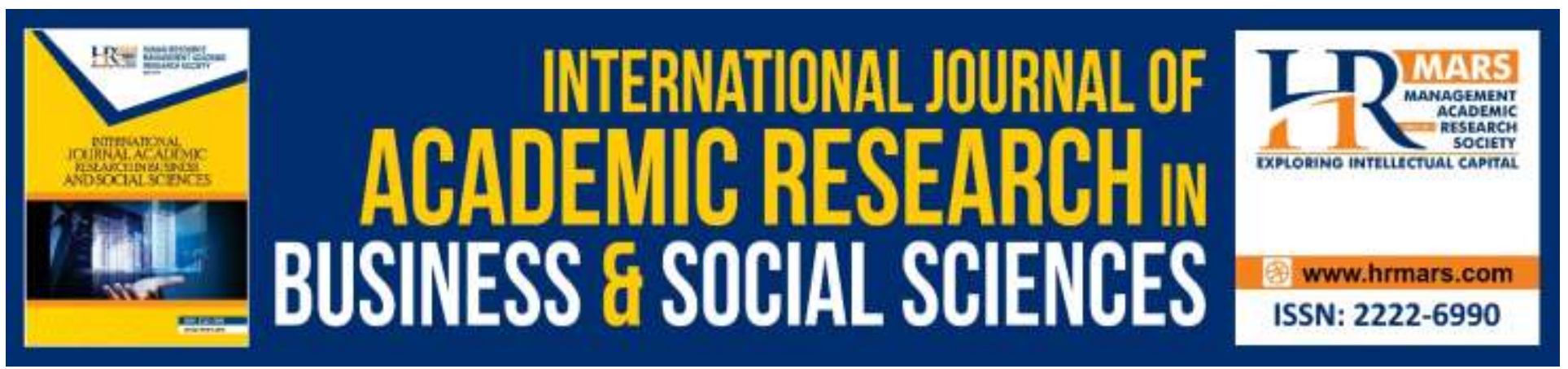

\title{
Investigating the Relationship Between Stress and Psychological Well-Being Among Foundation Students of UiTM
}

\author{
Melissa Malik, Norshiha Saidin, Roslinda Abd Wab, and Norshidah \\ Nordin
}

Centre of Foundation Studies, Faculty of Education, UiTM Malaysia

\begin{abstract}
The period of transition between high school and tertiary education can be overwhelming to preuniversity college students. It involves phases of adaptation as well as overcoming discomfort and challenges. In the process of adaptation, stress can be inevitable. Stress is known to influence one's psychological well-being and if not well managed, it can be detrimental to an individual's life and the individual may not be able to fully execute important daily tasks. College students may encounter stress in the dimensions of academic, financial, family, peers, and college surroundings with having to hold different roles and responsibilities as students. This situation may inevitably cause stress among students themselves. The stress experienced by these students can potentially affect their psychological well-being. Therefore, investigating students' level of stress and examining how stress can affect their psychological well-being is necessary. The current study sought to investigate the relationship of stress and psychological well-being of TESL Foundation students in UiTM. The survey questionnaires were randomly distributed to 222 participants. Student Stress inventory and Psychological Well-Being (PWB) scales were utilized to gather the data. Findings revealed an inversed moderate significant relationship between stress and psychological well-being among TESL foundation students. Implications and recommendations were suggested and discussed.
\end{abstract}

Keywords: Stress, Psychological Well-Being, College Students, Emotions, Achievement.

\section{Introduction}

The period of transition between high school and tertiary education can be overwhelming to pre-university college students. It involves a number of phases of adaptation and overcoming discomfort and challenges. Anbumalar et al. (2017) emphasise that the period of transition from high school to university or college underwent by students makes a crucial life experience. The process will absolutely allow for more opportunities of psychological development and learning experiences. However, in the process of transition and adaptation, stress can be inevitable. Winerman (2017) reported that there is a rise in the amount of students seeking for assistance due to stress at colleges and universities counselling centres. Stress is actually required as a natural response to alert the 
individuals of any potential danger (Garcia \& Miralles, 2017). Stress is known to influence one's psychological well-being. However, if it is not well managed, it can be detrimental to an individual's life and the individual may not be able to fully execute important daily tasks.

Different people will respond to stress differently. Studies conducted to identify relationship between stress and gender have yielded findings that indicate males and females respond to stress differently. For example, a research done by Dusselier et al. (2005) examine how stress is influenced by anxiety and other factors. The participants of this study were undergraduate students in the United States. They found that, generally, male students experience stress less frequently in the campus setting. In addition, they also found that factors such as health, personal, academic, and environmental elements also contribute to stress (Dusselier et al., 2005). Another study by Brougham et al. (2009) which also investigated level of stress among male and female college students in the United States showed that female college students experienced larger amount of stress in comparison to their male colleagues. Similarly, Misra and McKean (2000) investigated American undergraduate students and revealed findings that were consistent with previous studies that indicate higher academic stress and anxiety among female college students.

Sources of stress among college students can be divided into academic and non-academic factors such as financial, family, peers, college surroundings, and psychological attributes (Brand \& Schoonheim-Klein, 2009). Simultaneously, these college students also enter a new phase of developmental stage called young adulthood (Shkulaku, 2015). According to Erikson (1968), this is the stage where they encounter issues with moving away from home, relationships with others, career choice, etc. Thus, high level of stress is often inevitable during this period of time. Bedewy and Gabriel (2015) claim that stress levels may intensify in some students to the point of causing symptoms of anxiety especially during test and examination periods. In a study conducted by Baste and Gadkari (2014), the main cause of stress among majority of the students is academic factors. Following these are the physical, social, and emotional factors. Many students experiencing stress also recorded high scores of low self-esteem and nearly half of them obtained high scores on depression scales (Baste and Gadkari, 2014). If the stress level prevails for a long time, this can lead to more serious psychological problems in future and will affect the students' psychological wellbeing.

Psychological well-being can be conceptualised as a collection of positive affective states that refer to the concept of happiness, person's welfare, interests, and quality of life (Deci \& Ryan, 2008; Burris, Brechting, Salsman \& Carlson, 2009). As Huppert (2009, p.137) summarised, "psychological well-being is about lives going well. It is the combination of feeling good and functioning effectively." In essence, psychological well-being not only refers to happiness but also mental stability and socialability. As mentioned earlier, stress is a form of reaction that works as an alert system protecting humans from surrounding threats. When stress happens, the body will prepare itself by discharging hormones that escalates attentiveness and concentration. On the contrary, should the source of stress still lingers, stress hormones can last inside the body. Being exposed constantly to stress hormones can potentially cause a range of physical and psychological illnesses like obesity, cardiovascular disorders, skin disorders, anxiety attacks, and ultimately depression (Anbumalar et al., 2015). Research has shown that psychological stress can result in deterioration of immune functioning (Cohen, Miller, \& Rabin, 2001) and that it is a crucial factor that contributes to a wide range of illnesses, including cardiovascular disease (Jenkins, 1998), recurrent headaches (Marlowe, 1998), and the common cold (Cohen, Frank, Doyle, Skoner, Rabin, \& Gwaltney, 1998). If stress is 
managed effectively, chances of having these illnesses will decrease. Sarafino and Ewing (1999) emphasised that "being able to assess and reduce student stress is an important concern for college counselling and health centres because of students' many adjustments and physical health problems" (p. 76).

Based on the previous literature, not well-controlled stress may lead to physical illnesses and serious psychological issues among students. This can later impair their progress in studies and decrease their potentials of completing their tertiary education pursuits. The present study sought to further investigate the level of stress and psychological well-being among Malaysian university students. For the purpose of this study, UiTM foundation students were selected. The following are the research objectives of this study:

1) To examine the level of stress among foundation students of UiTM

2) To examine the dimensions of stress among foundation students of UiTM

3) To examine whether there is significant difference between stress and gender

4) To examine whether there is significant difference between psychological well-being and gender

5) To examine the relationship stress and psychological wellbeing among foundation students of UiTM.

\section{Methodology}

The study utilised a quantitative approach using a survey method which is descriptive in nature. In relation to the objectives of the study, a self-report questionnaire was utilised to collect information from the respondents. Adapted from Heubeck and Neill (2000) as well as Veit and Ware (1983), an instrument containing ten items was developed to measure psychological well-being. The items in the questionnaire required the respondents to rate how they had been feeling in the previous months on a six-point scale. Thus, high state of psychological well-being is assumed that an individual is stable psychologically in terms of mental health, happiness, and social-ability. In this study, the stress questionnaire was adapted from the one developed by Barreca and Hepler (2000) to gather the information of the respondents. It consists of 20 items of statements with three dimensions related to stress such as academic, finance, and emotions. Academic stress deals with attention, understanding of class, punctuality, concentration, completing the assignment, and passing the examination. Financial stress refers to financial support from parents and managing expenses, education debts, and budget. Emotional factor refers to individual's confidence, feelings of loneliness, and relationship with others. The Cronbach Alpha coefficient was found to be 0.783 . The samples were drawn from the Foundation students from the Centre of Foundation, UiTM, Dengkil. From 250 TESL foundation students who were required to complete the questionnaire, 222 of them responded and returned. Hence the response rate was $88.8 \%$. Pearson Correlation analysis was used as a tool to identify the significant relationship between stress and psychological well-being. In addition, Independent T-Test was also used to compare between the two variables and the personal variables. 
INTERNATIONAL JOURNAL OF ACADEMIC RESEARCH IN BUSINESS AND SOCIAL SCIENCES

Vol. 10, No. 14, Special Issue: WSTI2018 - Issues and Trends on Education, Science and Technology, 2020, E-ISSN: 2222 -6990 @ 2020 HRMARS

\section{Findings and Discussions}

Analysis on the levels of stress among Foundation students of UiTM

Table 1: The Levels of stress among Foundation students of UiTM

\begin{tabular}{lll}
\hline Level & Frequency & Percentage \\
\hline Low & 120 & 54.0 \\
Moderate & 102 & 46.0 \\
High & - & - \\
& & \\
\hline Total & 222 & 100 \\
\hline
\end{tabular}

Table 1 displays the levels of stress faced by the Foundation students of UiTM. The findings revealed that majority of them, that is, $54.0 \%$ (120) demonstrated low level of stress and 46\% (102) showed moderate level of stress. The result of this study is consistent with the study conducted by Tajularipin, Vizata, and Saifuddin (2009) as well as Kranz (2008). Stress can happen when the students' resources to cope with their state are exceeded by the combination of internal and external pressures (Seyle, 1956). Further analysis was conducted to examine each dimension of stress as tabulated in the following table.

Table 2: The dimensions of stress

\begin{tabular}{|l|l|l|}
\hline Stress dimensions & Mean & Std deviation \\
\hline Academic stress & 1.856 & $\mathbf{0 . 5 0 0}$ \\
\hline Financial stress & 1.127 & $\mathbf{0 . 8 0 2}$ \\
\hline \hline Physical and emotions stress & $\mathbf{1 . 9 5 2}$ & $\mathbf{0 . 7 3 1}$ \\
\hline
\end{tabular}

Mean indicators: Low: (less than 1.66); Moderate: (1.67- 3.32); High: (more than 3.3)

Table 2 illustrates the distribution of mean scores for stress dimensions among the Foundation students of UiTM. The result showed that mean scores for academic stress $(\mathrm{m}=1.856$, std dev $=0.500)$ and physical and emotional stress were perceived as moderate $(\mathrm{m}=1.952$, std dev= 0.731 ). This result suggests that generally, the respondents were more prone to have academic and physical and emotional stress as compared to financial stress. This finding is in line with a study done by Babar et al. (2004) where they found that the most prevailing stressors among college students were that of academics and examinations. Similarly, Kadapatti and Vijayalaxmi (2012) noticed that factors such as curriculum and study workload together with economic deprivation may be accountable for academic stress. On the contrary, financial was perceived as low level of stress $(\mathrm{m}=$ 1.127 , std dev $=0.802$ ). This result is also in line with a study conducted by Pariat, Rynjah, and Kharjana (2014). Most of these Foundation students have strong financial support from families and some receive financial aid from the Ministry of Education. Nevertheless, Pariat et al. (2014) stated that some of the financial stressors may include no financial support from family for pursuing studies, parents control the money spent, trouble managing a budget, insufficient money for paying personal smartphone bills, and learning material expenses such as printing and class projects. 
Analysis on the level of psychological well-being among the Foundation students of UiTM

Table 3: The Levels of psychological well-being among the Foundation students of UiTM

\begin{tabular}{lcc}
\hline Level & Frequency & Percentage \\
& & \\
\hline Low & 51 & 23.0 \\
Moderate & 153 & 68.9 \\
High & 18 & 8.1 \\
& & \\
\hline Total & 222 & 100 \\
\hline
\end{tabular}

Table 3 exhibits the levels of psychological well-being among the Foundation students of UiTM. The findings revealed that majority of them, that is, $68.7 \%$ (153) perceived moderate level of psychological well-being and only $8.1 \%$ (18) perceived high level of psychological well-being. On the other hand, about $23 \%$ (51) of the respondents perceived low level psychological well-being. This study suggests that the respondents perceived moderate state of psychological well-being, which indicate that they are mainly psychologically stable in terms of mental health, happiness, and socialability. It is interesting to note that about $23 \%$ of these students were experiencing low level psychological well-being indicating emotional and psychological instability. This finding is consistent with a study done by Zulkelfly and Baharudin (2010). They found that about $47.1 \%$ of the college students scored low level of psychological well-being indicating that a substantial amount of students are at an alarming state of psychological issues. Nonetheless, a positive psychological well-being among students are manifested through having the abilities to execute daily responsibilities, having challenging experiences that foster growth, being confident about ideas and opinions, and feeling that life has meaning and direction (Basson, 2015).

Analysis on significant differences between stress and gender Table 4: T-test analysis on psychological well-being and gender

\begin{tabular}{llllcc}
\hline \multirow{2}{*}{ stress } & Gender & mean & std dev & $t$ & sig \\
& Male & 1.637 & .5006 & 0.702 & 0.482 \\
\hline
\end{tabular}

As documented in the independent t-test shown in Table 4, the result reveals that female respondents show higher stress level (mean $=2.353$, std dev $=.8807$ ) than male counterparts (mean= 1.637 , std dev $=.5006)$. This finding is similar to the finding of previous studies conducted by Misra and McKean (2000), Dusselier et al. (2005), Brougham et al. (2009). Nevertheless, the result indicates that there was no significant difference between stress level and gender, where $t=0.702, p=0.482$. 
INTERNATIONAL JOURNAL OF ACADEMIC RESEARCH IN BUSINESS AND SOCIAL SCIENCES

Vol. 10, No. 14, Special Issue: WSTI2018 - Issues and Trends on Education, Science and Technology, 2020, E-ISSN: 2222-6990 @ 2020 HRMARS

Analysis on significant differences between psychological well-being and gender

Table 5: T-test analysis on psychological well-being and gender

\begin{tabular}{llllcc}
\hline & Gender & mean & std dev & $t$ & sig \\
PWB & Male & 2.353 & .8807 & 1.431 & 0.154 \\
& Female & 2.172 & .8167 & & \\
\hline
\end{tabular}

In accordance to the independent t-test presented in Table 5, the result reveals that male respondents show higher psychological well-being (mean $=2.353$, std $\mathrm{dev}=.8807$ ) than female counterparts $($ mean $=2.172$, std dev $=.8167$ ). Nevertheless, the result indicated that there was no significant difference between psychological well-being and gender, where $t=1.431, p=0.154$. In the previous research carried out by Duselier et al. (2005) and Brougham et al. (2009), female students show higher stress level than their male counterparts. Therefore, male students experience moderate or low level of stress, which may explain why they possessed higher level of psychological well-being.

Analysis on the relationship between stress and psychological well-being Table 4: Correlation Matrix between stress and psychological well-being Psychological well-being $r$

Stress

$-0.423 \quad 0.00$

The finding from the above Table 4 indicates a moderate and inverse relationship between psychological well-being and stress among the Foundation students of UiTM, where $r=-0.423, p=.00$. In other words, this suggests that if the students were able to reduce their stress level, hence, they might be able to increase their psychological well-being. However, the university authorities should exercise caution for the finding also implies that if sources of stress continue to prevail among students, there is a high possibility that it can lead to future psychological problems. Undeniably, stress is a clear risk factor that could lead to mental health problems and other physical illnesses. Stress that is not well-managed may also lead to deep impact on individual's physical and mental well-being, as well as various illnesses (Chandra and Batada, 2006). This finding supports the study conducted by Chen, Wong, Ran, and Gilson (2009) and Anand and Nagle (2016). Chida and Steptoe (2008) suggested that higher level of psychological well-being can be achieved through better management of daily stress. Ayodele et al. (2013) advised that, a person who is psychologically stable, are able to comprehend themselves and deals with the barriers in life as a result of being physically, mentally, and psychologically apt. Educational programmes and awareness campaigns regarding stress management can be conducted regularly among students through campus talks, meetings with academic advisors, and co-curricular activities. This will eventually assist the students to cope with stress and increase their level of psychological well-being.

\section{Conclusion}

The outcomes of this research study direct us to conclude that stress is very common among college students or students undergoing preparatory programmes before embarking on their first bachelor programme. In addition, the study also found that these Foundations students' level of 
psychological well-being was moderate. It was evident in this study that stress level influences negatively on the psychological well-being of the UiTM Foundation students. Generally, the respondents were more inclined to have academic, physical, and emotional stress as compared to financial stress. Therefore, educators and counsellors of the university need to conduct a psychological, social, and academic counselling for the students in order to reduce stress among them. In relations to academic stress, educators can help the students with providing more academic activities that include informative campaigns that advise students on strategies to excel academically while keeping stress at bay. They can also organise motivational talks to nurture and boost students' self-efficacy and confidence level particularly during their study period at colleges or universities.

\section{References}

Anbumalar, C., Dorathy, A. P., Jaswanti, V. P., Priya, D., \& Reniangelin, D. (2017). Gender Differences in Perceived Stress levels and Coping Strategies among College Students. International Journal of Indian Psychology, Vol. 4, (4), DIP:18.01.103/20170404, DOI:10.25215/0404.103

Baste, V. S., and Gadkari, J. V. (2014) Study of stress, self-esteem and depression in medical students and effect of music on perceived stress. Indian Journal of Physiology and Pharmacology 58: 298-301.

Bedewy, D., and Gabriel, A. (2013) The development and psychometric assessment of a scale to measure the severity of examination anxiety among undergraduate university students. International Journal of Educational Psychology 2: 81-104.

Brand, H., and Schoonheim-Klein, M. (2009) Is the OSCE more stressful? Examination anxiety and its consequences in different assessment methods in dental education. European Journal of Dental Education 13: 147-153.

Zulkefl, Y. N. S., and Baharudin, R. (2010). Using the 12-item General Health Questionnaire (GHQ12 ) to assess the psychological health of Malaysian college students. Global Journal of Health Science, 2(1): 73-80.

Babar, T. S., Kahloon, A., Kazmi, M., Khalid, H., Nawaz, K., Khan, N. A., and Khan, S. (2004). Students, Stress and Coping Strategies: A Case of Pakistani Medical School Community Health Sciences Department, Aga Khan University (AKU), Karachi, Pakistan Education for Health, 17( 3), 346353

Kadapatti, M. G., and Vijayalaxm, A. H. M. (2012) Stressors of academic stress - a study on preuniversity students. Indian J.Sci.Res.3(1) : 171-175,

Pariat, L., Rynjah, A., and Kharjana, G. (2014) Stress Levels of College Students: Interrelationship between Stressors and Coping Strategies. Journal of Humanities and Social Science Volume 19, Issue 8, Ver. III , PP 40-46

Basson, M. J. (2015). Pathways to flourishing of pharmacy students. PHD thesis. Vanderbiljpark: North-West University. Retrieved from the internet dated 5 December 2018 http://www.scielo.org.za/scielo.php?script=sci_arttext\&pid=S2071-07632016000100008

Selye, H. (1956). The Stress of Life. New York: McGraw-Hill

Ayodele, Olanrewaju, K., \& Ezeokoli, R. N. (2013) The relationship between campus social life and psychological wellbeing among Babcock university undergraduates. Research on Humanities and Social Sciences Vol.3, No.10

Chida, Y., \& Steptoe. (2008) A. Positive psychological well-being and mortality: a quantitative review of prospective observational studies. Psychosomatic Medicine; 70(7), 741-756 
Barreca and Hepler. (2000). "Stress Questionnaire". Retrived from

https://www.tru.ca/hsafety/workinglearningsafely/stress/s tressquestionnaire.html

Anand, K., and Nagle, Y. K. (2016) Perceived Stress as Predictor of Psychological Well-being among Indian Youth. The International Journal of Indian Psychology Volume 3, Issue 4, No. 68

Chandra, A., and Batada, A. (2006) Exploring stress and coping among urban African American adolescents: the Shifting the Lens study. Prev Chronic Dis 3: A4

Kranz, P. (2008). Perceived Stress by students in pharmacy curriculum. Education .129(1). Pp.71-78.

Wilks, S. E. (2008). Resilience amid academic stress: The moderating impact of social support among Social Work Students. Advances in Social Work, 9 (2), 106-125

Chen, H., Wong, Y., Ran, M., and Gilson, C. (2009). Stress among Shanghai University Students. Journal of Social Work. 9(3). pp. 323-344. -

Tajularipin, S., Aminuddin, H., Vizata, S., and Saifuddin, A. (2009). The level of stress among students in Urban and rural secondary schools in Malaysia. European Journal of Social Sciences. 10(2). pp. 43-65. 